\title{
Cost Performance Report for the ASTD Reuse of Concrete within DOE from D\&D Project
}

September 2000

Idaho National Engineering and Environmental Laboratory Bechtel BWXT Idaho, LLC 


\section{Cost and Performance Report for the ASTD Reuse of Concrete within DOE from D\&D Project}

September 2000

\section{Idaho National Engineering and Environmental Laboratory} Idaho Falls, Idaho 83415

Prepared for the

U.S. Department of Energy

Under DOE Idaho Operations Office

Contract DE-AC07-99ID13727 


\begin{abstract}
This cost and performance report describes the Accelerated Site Technology Deployment project that developed the Protocol for Development of Authorized Release Limits for Concrete at U.S. DOE Sites, which identifies the steps for obtaining approval to reuse concrete from Deactivation and Decommissioning of facilities. This protocol compares the risk and cost of various disposition paths for the concrete and follows the authorized release approach described in the DOE's draft handbook, Controlling Release for Reuse or Recycle of Property Containing Residual Radioactive Material. This approach provides for the development of authorized release limits through a series of prescribed steps before approval for release is granted. A case study was also completed on a previously decommissioned facility.
\end{abstract}




\section{SUMMARY}

The purpose of the Reuse of Concrete within DOE from D\&D project was to develop a protocol that will assist DOE sites in releasing concrete for reuse. Current regulations allow for release of surface-contaminated materials that fall below certain radioactivity levels and the possible release of volumetrically contaminated materials or higher levels of surface-contaminated materials on a case by case basis. In all cases, an ALARA analysis is required as part of the release process. This protocol, titled the Protocol for Development of Authorized Release Limits for Concrete at U.S. Department of Energy Sites, provides a standardized approach, including an ALARA analysis, for evaluating the risks of releasing volumetrically contaminated or higher levels of surface-contaminated concrete, so new release standards can be proposed and set, allowing reuse of the concrete material.

The protocol provides a method to perform a detailed analysis of the dose and cost impact for various disposition alternatives. Once the dose and cost impact of the various alternatives has been estimated, the protocol outlines the steps required to propose new release standards that allow release and reuse of the concrete material.

In order to evaluate the dose impacts of reusing radioactively contaminated material, the measured radiation levels $\left(\mathrm{pCi} / \mathrm{g}\right.$ or DPM/100 $\mathrm{cm}^{2}$ ) must be converted to estimated dose ( $\mathrm{mrem} / \mathrm{yr})$ received by affected individuals. The dose depends on the amounts and types of isotopes present and the time, distance, and method of exposure (e.g., inhalation, ingestion, or exterior exposure). For each disposition alternative, the protocol provides a systematic method to evaluate the dose impact on the affected individuals. Likewise, the cost impacts of reusing the concrete are dependent on the disposition alternative chosen and on the extent and type of contamination.

This paper summarizes the project and its accomplishments, beginning with a description of the need for a concrete protocol. It then details the project objective, outlines team roles, discusses existing standards for release of concrete, and summarizes the concrete protocol. It concludes with a summary and analysis of the case study, a description of the protocol's distribution, and several sections about the overall success of the project, including Project Performance Results, Accomplishments, and Cost Performance. 


\section{ACKNOWLEDGMENTS}

Support and input from the following team members contributed significantly to the completion and success of this project. We extend our gratitude to them for all their efforts.

Jane Powell

Chelsea Hubbard

Kevin Kostelnik

Brad Frazee

Doug Larsen

John Marthis

Dennis Tuckness
Robert Vagnetti

Gihad Aljaoushi

Marsha Gunderson

Tom Thiel

Lawrence Auman

Walker Howell

Henry Peterson 


\section{CONTENTS}

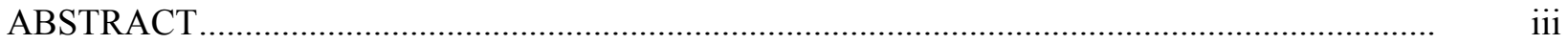

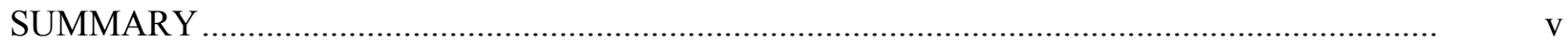

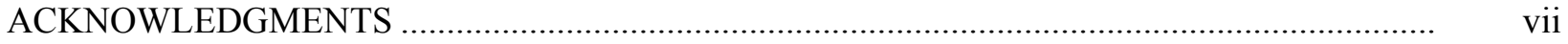

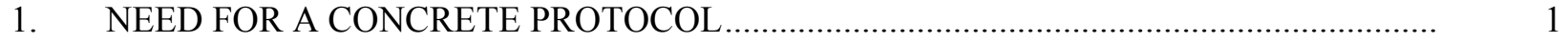

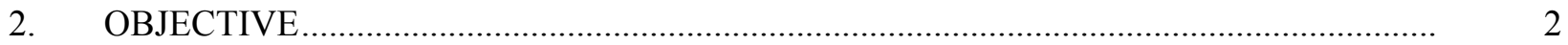

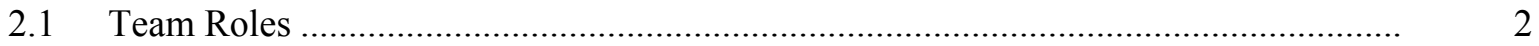

3. EXISTING RELEASE STANDARDS AND REGULATIONS ......................................... 3

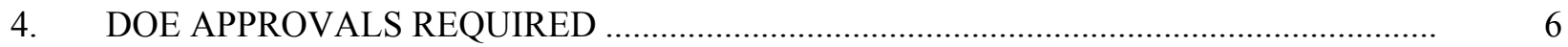

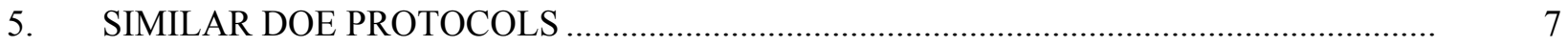

6. DETAILED DESCRIPTION OF GENERAL PROTOCOL ....................................................

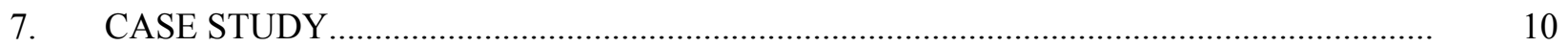

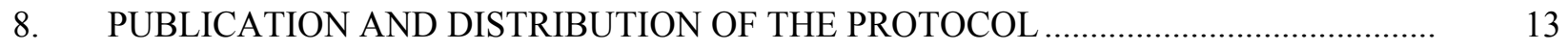

9. PROJECT PERFORMANCE RESULTS ..................................................................... 14

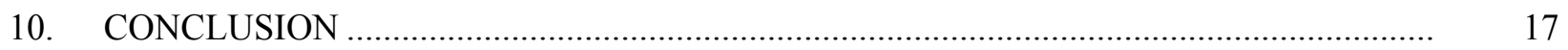

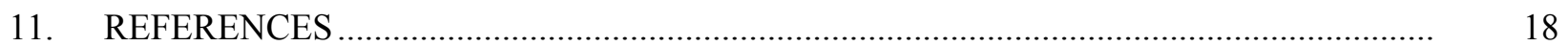

Appendix A-Authors/Biographies

\section{FIGURES}

1. Authorized Release Process Flow Diagram (Source: DOE 1997) ${ }^{5}$

\section{TABLES}

1. Characterization Data for Trickle Filter, Primary Clarifier, Secondary Clarifier, and Pump House

2. INEEL Specific Summary of Cost and Radiological Impacts for Different Alternatives....... 


\section{Cost Performance Report for the ASTD Reuse of Concrete within DOE from D\&D Project}

\section{NEED FOR A CONCRETE PROTOCOL}

Many facilities in the Department of Energy (DOE) complex containing large amounts of concrete are scheduled for Decontamination and Decommissioning (D\&D) over the next several years. Much of the concrete in these buildings is either lightly contaminated with radiation or completely uncontaminated. Since concrete is porous and no standardized method or levels for releasing volumetrically contaminated concrete exist, much of this uncontaminated material will be disposed of at a very high cost as radioactive waste. A study ${ }^{1}$ performed by Vanderbilt University for the DOE showed that the volume of concrete within the DOE complex is approximately $380,000,000$ cubic feet. In addition, the study indicated that approximately $98 \%$ of this concrete is not radioactively contaminated, and that re-using it rather than disposing of it as radioactive waste would save a minimum of $\$ 110$ million, and possibly up to $\$ 1.3$ billion. At the INEEL alone, where facilities contain approximately $219,142 \mathrm{~m}^{3}$ of uncontaminated concrete, recycling would potentially save $\$ 70$ thousand (Kenoyer and LaBuy 1994$)^{8}$.

During fiscal year 2000, Rocky Flats Environmental Technology Site (RFTS) expressed an interest in applying the Protocol for Development of Authorized Release Limits for Concrete to facilitate reuse of concrete material. In addition, during a presentation of the protocol and project at the International Decommissioning Symposium (IDS) 2000 conference, representatives from Oak Ridge National Laboratory (ORNL) and a private company from the United Kingdom expressed a need for the protocol. At ORNL, the protocol would have been immensely helpful on a project completed in the last fiscal year, and in the UK, it may apply to upcoming projects. 


\section{OBJECTIVE}

In order to address the issue of concrete reuse, the Accelerated Site Technology Deployment Program (ASTD) initiated the Reuse of Concrete within DOE from D\&D project. The purpose of the project is to develop a protocol for the reuse of concrete within the DOE system. The protocol is a decision tool that

- $\quad$ outlines the current regulations and standards governing releases of surface- and volumetrically- contaminated concrete

- $\quad$ evaluates the risks and costs for various disposition alternatives

- $\quad$ converts from measured radiation levels to dose, so that the risks for each alternative can be evaluated

- $\quad$ outlines the steps required to define authorized limits for the release of concrete material.

The concrete protocol is based on the Draft Handbook for Controlling Reuse of Non-real Property Containing Radioactive Material, and it meets all applicable DOE orders and requirements. The protocol provides a standardized method of evaluating the risks and costs of reusing concrete material within the DOE complex, and provides a method to develop release standards, which may lead to reuse of some of this material and significant cost savings.

\section{$2.1 \quad$ Team Roles}

A team of engineers and professors from Argonne National Laboratory-East (ANL-E), Vanderbilt University, and the Idaho National Engineering and Environmental Laboratory (INEEL) is working to complete the project. Each of the three locations contributing to the team was chosen because of particular experience and qualifications. ANL-E wrote the protocol for the free release of concrete. They were well suited to this task because they had previously developed a similar protocol for release of scrap metals. The INEEL was chosen to work on this project because it contains a large amount of concrete material in facilities scheduled for D\&D. The project team operated under management of the INEEL. Together, the INEEL and ANL-E worked to understand how the protocol would be implemented during D\&D operations at the INEEL. Vanderbilt University provided information about DOE concrete, since they previously carried out a comprehensive study of concrete within the DOE complex, after which they published Reuse of Concrete from Contaminated Structures ${ }^{1}$, a summary of the results of their study. The document provides helpful information concerning the amount, type, and contamination levels of concrete on DOE sites, including the amount of concrete with potential for reuse.

To assist with development of the protocol, INEEL team members also provided useful information to ANL-E, including existing INEEL release documents and regulations, technical information about INEEL concrete D\&D technologies, radiation contamination summaries, and descriptions of radiation detection equipment. To help with the case study, the INEEL provided information about possible application facilities, INEEL processes and regulations, INEEL facilities and concrete, and cost and production rates of concrete operations.

When ANL-E finished writing the concrete protocol, it corresponded with the INEEL to test the finished product in planning D\&D of an INEEL facility. Since the scope of D\&D work at the INEEL during the time frame of the concrete free release project did not include any concrete-containing facilities, the protocol was deployed in analysis of a facility that had been decontaminated and decommissioned earlier. The results of this study are summarized in the Case Study section. 


\section{EXISTING RELEASE STANDARDS AND REGULATIONS}

Within the authorized release process, it is required that no action should cause individual doses to a member of the public in excess of the primary dose limit of $100 \mathrm{mrem}$ total effective dose equivalent in one year (DOE 1990) ${ }^{4}$. Because primary dose limit is for all sources, a DOE source dose constraint of one quarter of the primary dose limit (i.e., $25 \mathrm{mrem} / \mathrm{yr}$ ) is used. DOE requires that all releases and exposures to the public be controlled to ensure that they do not exceed applicable dose limits and are, in fact, as low as reasonable achievable (ALARA). Releases are to be assessed in a manner consistent with the DOE ALARA process for protection of the public and environment (DOE 1997) ${ }^{5}$. As such, authorized limits for annual dose from the release of concrete should be as far below $25 \mathrm{mrem}$ as is practicable. This dose constraint of $25 \mathrm{mrem} / \mathrm{yr}$ represents an upper bound or "cap" for ALARA-based authorized limits for release of concrete containing residual radioactive material; therefore, an ALARA analysis is conducted in the assessment of potential release options to support the final authorized release option selected for the concrete. It is DOE's goal to establish release limits that control exposures so anticipated doses to members of the public are not more than a few mrem/yr above background (Kamboj et al 2000) ${ }^{7}$.

DOE Order 5400.5, "Radiation Protection of the Public and Environment" (DOE 1990) ${ }^{4}$, as amended, which was first issued on February 8, 1990, prescribes release standards for surfacecontaminated materials. Specifically, it defines the contamination levels allowed for each isotope that equate to doses of less than 1 millirem (mrem) per year to the maximally exposed individual (MEI). Authorized limits may be derived and approved by DOE Field Office managers without EH-1 approval if certain conditions are met (Arnish et al., 2000) ${ }^{6}$. One of the conditions is that the release of the concrete material will not cause a maximum individual dose to a member of public in excess of $1 \mathrm{mrem}$ in a year or a collective dose of more than 10 person-rem in a year.

For volumetrically contaminated materials, no equivalent standard exists. Because of this, authorized releases of volumetrically contaminated material are allowed on a case-by-case basis under Order 5400.5, which DOE has proposed to be codified in Title 10, Part 834 of the Code of Federal Regulations (Chen 1999a) ${ }^{2}$. In order to release materials using these documents, authorized release limits must be developed using a series of prescribed steps, including defining radiological characteristics, applying ALARA, obtaining approval from DOE, and obtaining concurrence by appropriate stakeholders.

In addition to these standards (Order 5400.5 and 10 CFR 834), DOE published a draft handbook in 1997, titled Controlling Release for Reuse or Recycle of Property Containing Residual Radioactive Material (DOE 1997) ${ }^{5}$, which clarifies the steps required for release. The handbook outlines a ten-step process for releasing non-real property containing residual radioactive contamination. Non-real property generally includes removable materials, while real property consists of real estate and facilities. The flowchart in Figure 1 depicts the ten-step process, which consists of the following steps:

1. Characterize property and prepare a description

2. Determine whether applicable authorized or supplementary limits exist

3. Define authorized or supplemental limits needed

4. Develop authorized or supplemental limits

5. Compile and submit application for DOE Operations Office approval

6. Document approved limits in the public record 


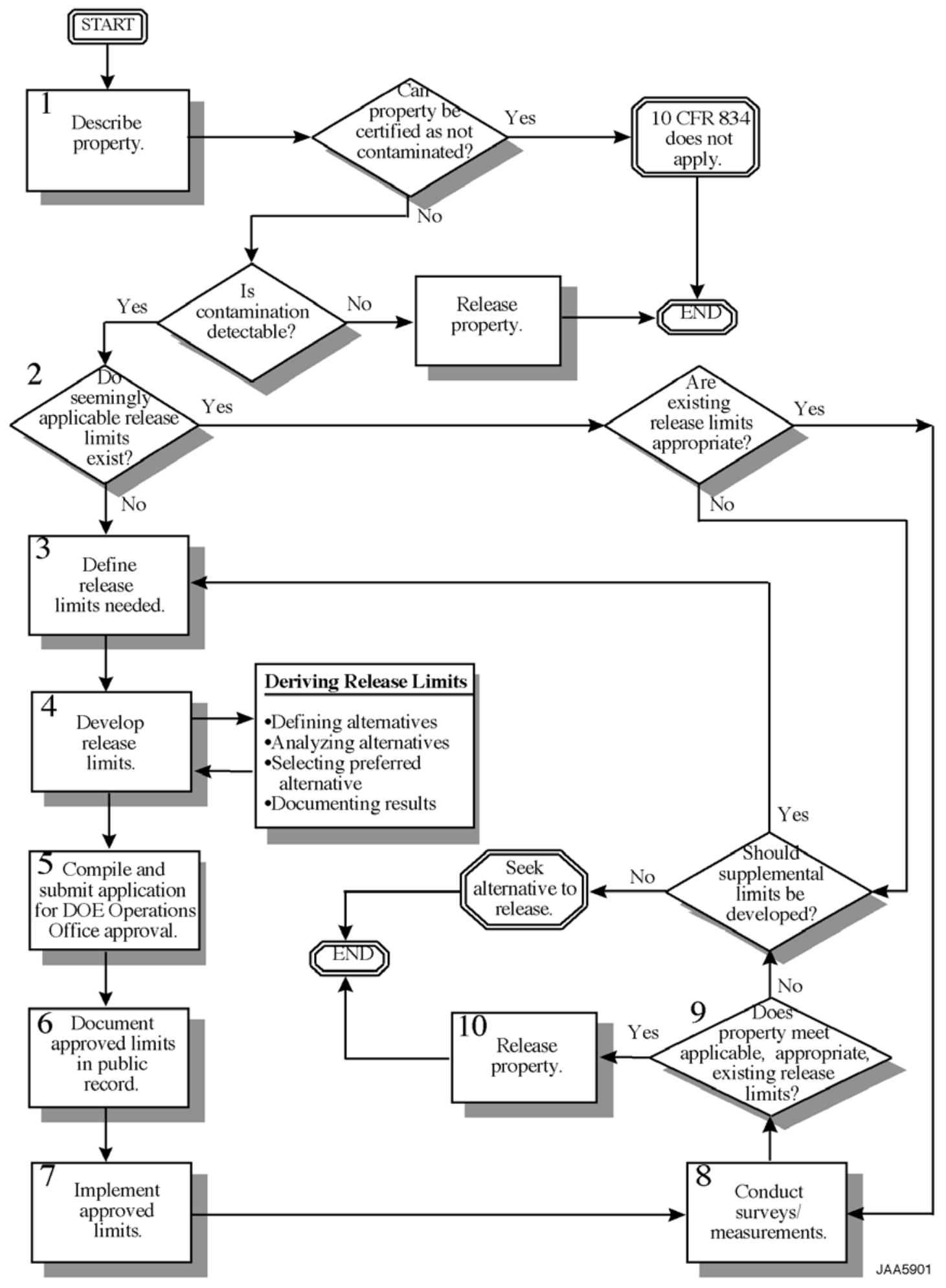

Figure 1. Authorized Release Process Flow Diagram (Source: DOE 1997) 
7. Implement improved limits

8. Conduct surveys/measurements

9. Verify that applicable authorized or supplemental limits have been met

10. Release property.

The protocol developed under this project is based on these documents and defines a methodology for developing release standards for volumetrically contaminated concrete by allowing an evaluation of the dose and cost associated with the proposed release.

Releases of volumetrically contaminated material that meet the expected dose limits prescribed for surface-contaminated materials (less than $1 \mathrm{mrem} / \mathrm{yr}$ to the MEI) are more likely to be accepted and approved than releases involving higher dose rates. However, with the lack of a release standard, each release of volumetrically contaminated concrete is defining a new release limit and requires appropriate approvals before implementation. 


\section{DOE APPROVALS REQUIRED}

Materials containing only surface contamination can be released with the appropriate DOE field office approval; however, release of materials and approval of authorized limits for materials with volumetric contamination requires approval from the Office of Environment, Safety, and Health (EH-1) unless certain conditions are met. If the release will not cause an MEI dose to a member of the public in excess of $1 \mathrm{mrem} / \mathrm{yr}$ or a collective dose of more than 10 person-rem/yr, records of the release are made per DOE Order 5400.5, DOE survey guidelines are maintained, and required documentation (as outlined in Section 2.5 of the protocol ${ }^{6}$ ) is submitted to EH-1 within the required time frames, the DOE field office can approve release of volumetrically contaminated material.

One of the difficulties of releasing volumetrically contaminated material is that it is difficult to measure the extent of the contamination. When applying the protocol, the depth of contamination is considered based on the previous use of the concrete (for example, was the concrete exposed to contaminated water, which may have led to increased penetration of contaminants) and is used to estimate the overall amount of contamination present. The protocol assumes that the concrete is still in its original state and has not been crushed, so history and surface surveys or samples can provide an estimate to the depth and extent of contamination. Taking samples at depth (core drilling or boring) can also be done, but it sometimes spreads contamination into the depth during the process, making the data gathered invalid. Because of this, the protocol relies on surface surveys and samples, and estimates the depth of contaminant penetration based on the radiological history of the facility. 


\section{SIMILAR DOE PROTOCOLS}

Although it does not address release standards and is more of a community impact assessment procedure for release of non-contaminated materials, a protocol with a similar title was developed at RFETS. There, a protocol for reuse of concrete that meets existing surface contamination release limits was developed and implemented in fiscal year 1999 and fiscal year 2000. The protocol, titled the $R F C A$ Standard Operating Protocol for Recycling Concrete, focuses on evaluating and mitigating impacts on the public and the environment from reusing non-contaminated concrete as roadbed material. It considers factors like fugitive dust, noise levels, and acidity of run-off water from the concrete material. This protocol provides useful information regarding the impact of reusing clean materials on nearby communities, and it is not the same as the protocol developed under the Reuse of Concrete within DOE from D\&D project. 


\section{DETAILED DESCRIPTION OF GENERAL PROTOCOL}

Using data provided by the INEEL, a concrete study performed by Vanderbilt University, and their previous experience with writing a scrap metal reuse protocol, Argonne National Laboratory-East developed a standardized protocol for the free release of concrete that will become a useful decisionmaking guide for D\&D project managers at all DOE facilities. The protocol consists of four major sections: 1. Introduction, 2. Authorized Release Protocols for Concrete, 3. ALARA Methodology, and 4. References. In addition, the document includes five appendices: A. Authorized Release Application, B. Decontamination Module, C. Transportation Unit-Cost and Dose Factors, D. Reuse Module Unit-Dose Factors, and E. Disposal Module Unit-Dose Factors.

The introduction explains the protocol's basis and purpose and provides general background information, including a summary of existing regulations and current release standards for surfacecontaminated material. Section Two, the Authorized Release Protocols for Concrete, is a step-by-step guide for developing release limits for concrete. It references Appendix A, the actual application forms for release of concrete, and explains each section of the application in detail to assist project managers and other protocol users in completing the forms. It includes a flow chart (see Figure 1) describing the general ten-step process of authorizing material for free release presented in the draft DOE handbook Controlling Release for Reuse or Recycle of Property Containing Residual Radioactive Material (DOE $1997)^{5}$, which is the basis for the concrete protocol.

To begin, the D\&D manager must characterize property and prepare a physical description and radiological history of the surplus facility. The next part of the protocol helps the manager determine whether release limits - either authorized or supplemental - exist. If limits do not exist (as is usually the case for concrete or other volumetrically contaminated material) or do not apply, it will be necessary to define free release limits for the concrete being analyzed. The next portion guides the protocol user through the ALARA analysis and development of authorized or supplemental limits for seven major disposal alternative options.

Alternative A involves decontamination of concrete, disposal of low-level waste (LLW), and reuse of decontaminated material in roadbeds. Alternative B is defined by crushing concrete without decontamination and reusing it as roadbed material. Alternative $\mathrm{C}$ allows decontamination of concrete, disposal of LLW, demolition of structure, and disposal of decontaminated material or reuse of it as backfill. In Alternative D, the concrete is demolished and either disposed of as construction debris in a non-radioactive sanitary landfill or reused as backfill. No decontamination is completed with this option. Option $\mathrm{E}$ is similar to $\mathrm{D}$ in that no decontamination is performed, but in this case, all concrete material is demolished and disposed of as LLW. Alternative F is to decontaminate the facility and reuse it. Finally, alternative $\mathrm{G}$ includes two sub-options: demolish and decontaminate the concrete material or structure and entomb the demolished material or demolish without decontamination and entomb the demolished concrete.

Theoretically, any D\&D project could be classified under one of these categories, either as an exact match, or some sub-alternative of the more general heading. After completing the portion of the application for one possible alternative, the manager may either evaluate another alternative in the same manner or move on to summarizing the results of alternative analysis. For each alternative examined, the manager evaluates associated costs and radiological doses for fast comparison of all possible options. Based on the results of this ALARA analysis, the best alternative is selected. Next, the protocol user will propose to set new authorized release limits in terms of concentration for the radionuclide profile, which was listed earlier in the application, for the chosen alternative. Now that analysis of options and associated costs and risks has been completed, the D\&D project manager will be able to compile and submit an application for approval by the DOE Operations Office directly overseeing the activities wherein release is requested. 
Limitations or restrictions on use of the concrete material should be recorded on the application form, as should comments or recommendations by other federal or state agencies, and a copy of appropriate survey protocols should be attached. Once release limits have been approved, they must be made a part of the public record, since DOE emphasizes the importance of public participation in operating programs, planning activities, and making decisions. In addition, site-specific documentation requirements and procedures should be followed. Following this documentation, approved limits can be implemented.

Implementation may require development of new or modified site-specific procedures. Once these procedures are developed, the next step is to conduct surveys according to the appropriate protocols in order to either verify that residual radioactive concentrations do not exceed release limits or to determine whether radioactivity can be detected. The final step that must be carried out before concrete can be released is to verify that concrete material meets authorized release limits. Concrete that does not meet existing applicable limits and for which no supplemental limits are developed cannot be released. Results of the survey will be compared to approved release limits, and the results of this comparison documented. When all release requirements have been met, the concrete can be released for reuse if it meets certain conditions. The Protocol is designed to ensure that these conditions are fulfilled.

The responsible DOE or contractor personnel must verify that: 1 . Concrete material to be released has been appropriately surveyed, 2. Residual radioactive material on concrete surface or interior meets acceptable release limits, 3 . Required documentation has been completed, and 4 . The owner or recipient of released material is properly notified of its radiological status and the availability of documentation. In addition, responsible personnel must verify and document compliance with other applicable laws, policies, and regulations. Finally, the concrete is released.

Section 3 of the Concrete Protocol explains the ALARA methodology used in determining release conditions. ALARA analysis includes calculating costs and radiation doses for each of the alternatives in Section 2. Radiation doses, which are estimated according to unit-dose factors, are evaluated only for non-radiological workers, since radiological workers are already part of a radiation protection program. Cost estimates are based on unit-cost factors. Appendices B through E list both unit-cost and unit-dose factors.

More specifically, Section 3 contains a subsection to describe each of five modules that compose the alternatives presented in Section 2. The modules included are Decontamination, Demolition/Crushing, Packaging/Transporting, Reuse, and Disposal/Entombment. Most of the module subsections also include other subsections. Decontamination Efficiency, Waste Generation, and Decontamination are all subsets of the Decontamination subsection. Under Packaging/Transportation, the protocol user finds subsections entitled Packaging/Transportation Costs, Transportation Dose-Driver Scenario, and Transportation Dose to Persons along the Transportation Corridor. The Reuse subsection includes Construction Worker Scenario and Building Reuse Scenario. Finally, Disposal/Entombment comprises sections called Disposal Costs, Landfill Worker, and Future Resident. The purpose of Section 3 of the Concrete Protocol is to ensure that under each option for dealing with concrete, affected persons receive the smallest dose of radiation possible, within reason, per ALARA.

Appendices B through E are a collection of cost and dose data pertaining to the modules outlined in Section 3. Information relating to cost and dose for a variety of decontamination, demolition, transporting, reuse, and disposal methods is presented in the form of a series of tables. 


\section{CASE STUDY}

In order to test the protocol, a case study was performed at the INEEL. Since no facilities containing contaminated concrete were decommissioned during the time frame of the project, the case study was performed on a facility where decommissioning had already been completed. In this way, the protocol could be tested, and the D\&D project managers could use the results of the study to determine if the disposition alternatives chosen were the most cost effective ones.

The INEEL Sewage Treatment Plant (STP) at Central Facilities Area (CFA) was selected for the case study. This facility was ideal, because it included many concrete structures with different isotopes and contamination levels. Structures that were part of the designated surplus facility include a septic tank, sludge drying bed, and drain field with four distribution areas constructed by the Navy in 1944; and a pumping station, sludge drying beds, trickling filter, primary and secondary clarifiers, and digester constructed in 1953.

Before beginning D\&D at any site, crews must characterize associated facilities and surrounding areas. At the Sewage Treatment Plant, workers collected samples from structures and tested them for radioactive and chemical contaminants. They analyzed surface samples, or smears, to identify removable radioactive contamination, and they performed radiological surveys on and inside the structures to identify fixed surface contamination. The Ludlum 2A tested for beta and gamma contamination, and the NE Technology Electra identified alpha contamination. Smears were counted on a gas proportional counter. Contamination of construction material was assumed to be equal to or less than the contamination at the surfaces inside of piping or containment. The following table shows the radionuclides detected in sediment or liquid samples from different structures (Klassy 1997). Some radionuclides show two results: the first is alpha analysis, and the second is gamma analysis. No survey data was available for the Pumping Station. No direct sample analysis was done on the Digester, but beta/gamma scans showed contamination levels ranging from $4000-40,000 \mathrm{dpm} / 100 \mathrm{~cm}^{2}$. 
Table 1. Characterization Data for Trickle Filter, Primary Clarifier, Secondary Clarifier, and Pump House.

\begin{tabular}{|c|c|c|c|c|c|c|}
\hline \multirow[b]{2}{*}{ Radionuclides } & \multirow{2}{*}{$\begin{array}{c}\text { Trickle Filter } \\
\begin{array}{c}\text { Sediment } \\
(\mathrm{pCi} / \mathrm{g})\end{array} \\
\end{array}$} & \multirow{2}{*}{$\begin{array}{c}\text { Primary } \\
\text { Clarifier } \\
\text { Vacuum } \\
\text { debris, } \mathrm{pCi} / \mathrm{g}\end{array}$} & \multicolumn{2}{|c|}{ Primary Clarifier } & \multirow{2}{*}{$\begin{array}{c}\begin{array}{c}\text { Secondary } \\
\text { Clarifier }\end{array} \\
\begin{array}{c}\text { Liquid } \\
(\mathrm{pCi} / \mathrm{L})\end{array} \\
\end{array}$} & \multirow{2}{*}{$\begin{array}{c}\text { Pump House } \\
\begin{array}{c}\text { Sediment } \\
(\mathrm{pCi} / \mathrm{g})\end{array}\end{array}$} \\
\hline & & & $\begin{array}{l}\text { Sediment } \\
(\mathrm{pCi} / \mathrm{g})\end{array}$ & $\begin{array}{l}\text { Liquid } \\
(\mathrm{pCi} / \mathrm{L})\end{array}$ & & \\
\hline Am-241 & 0.302 & 0.0405 & $0.552,0.55$ & & 0.72 & 0.0285 \\
\hline $\mathrm{Pu}-238$ & 0.786 & 0.186 & 0.27 & & & 0.021 \\
\hline Pu-239 & 0.27 & 0.04435 & 0.41 & & & 0.012 \\
\hline Ra-226 & 6.6 & 5.57 & 6.9 & & & 6.1 \\
\hline $\mathrm{U}-234$ & 5.14 & 7.57 & 7.78 & 0.22 & 2.23 & 5.28 \\
\hline $\mathrm{U}-235$ & 0.342 & $1.17,0.43$ & $0.534,0.63$ & & $0.089,25.0$ & 0.357 \\
\hline $\mathrm{U}-238$ & 16.2 & 5.8 & 15.8 & 0.156 & 1.24 & 8.49 \\
\hline Sr-90 & 8.11 & 11.0 & 0.609 & 7.85 & 4.77 & 7.56 \\
\hline Cs-137 & 74.0 & 19.3 & 1.48 & 26.3 & 19.0 & 2.8 \\
\hline Co-60 & 233 & 10.2 & 3.96 & & & 16.8 \\
\hline Eu-152 & 0.59 & & & & & 0.595 \\
\hline Eu-154 & & & & & & 0.36 \\
\hline $\mathrm{Ru}-103$ & 0.27 & & & & & \\
\hline \multirow{3}{*}{$\begin{array}{l}\text { beta/gamma scan } \\
(\mathrm{dpm} / 100 \mathrm{~cm} 2) \\
\text { range }\end{array}$} & $1200-9600$ & $1200-25000$ & & & $1200-80000$ & $\begin{array}{l}2000-50000 \\
\text { (main floor) }\end{array}$ \\
\hline & & & & & & $\begin{array}{l}800-15000 \\
\text { (basement) }\end{array}$ \\
\hline & & & & & & $\begin{array}{c}2400-32000 \\
\text { (roof) }\end{array}$ \\
\hline
\end{tabular}

Through completing this hypothetical case study, ANL-E engineers determined that Alternative B - Crush and Reuse without Decontamination - and Alternative D-Demolish and Dispose at C\&D Landfill — cost less than the three other evaluated options. Except in the case of the trickle structure, these alternatives would result in a dose less than $1 \mathrm{mrem}$ to the nonradiological workers. If concrete cannot be reused on site, decontaminated concrete can be free released for disposal at a construction and debris (C\&D) landfill. However, since for the trickle filter Alternative D would result in doses greater than 1 $\mathrm{mrem} / \mathrm{yr}$ to the future resident at a C\&D landfill, it could not be used at the INEEL. It should be noted that the main contributor to radiological doses is Cobalt-60, which has a half-life of 5.27 years. The starting point for this analysis was the characterization done in 1996. Co-60 would have decayed to $60 \%$ of its initial contamination level in four years, so future resultant doses (today and later) will be significantly less than the values reported in this analysis. The following table summarizes cost and radiation dose for each alternative evaluated in the case study. 
Table 2. INEEL Specific Summary of Cost and Radiological Impacts for Different Alternatives.

\begin{tabular}{|c|c|c|c|c|c|c|}
\hline Structure & Alternative & Total Cost & $\begin{array}{c}\text { Driver dose } \\
(\mathrm{mrem})\end{array}$ & $\begin{array}{c}\text { Population } \\
\text { (person-rem) }\end{array}$ & $\begin{array}{l}\text { Worker } \\
(\text { mrem })\end{array}$ & $\begin{array}{c}\text { Future resident } \\
(\mathrm{mrem})\end{array}$ \\
\hline \multirow[t]{5}{*}{ Trickle Filter } & A & $\$ 51,366$ & None & $6.33 \mathrm{E}-06$ & $8.00 \mathrm{E}-01$ & none \\
\hline & $\mathrm{B}$ & $\$ 14,280$ & None & none & $1.92 \mathrm{E}+00$ & none \\
\hline & $\mathrm{C}$ & $\$ 53,281$ & $2.86 \mathrm{E}-03$ & $7.23 \mathrm{E}-06$ & $1.49 \mathrm{E}-02$ & $1.47 \mathrm{E}+00$ \\
\hline & $\mathrm{D}$ & $\$ 16,402$ & $6.87 \mathrm{E}-03$ & $2.17 \mathrm{E}-06$ & $3.58 \mathrm{E}-02$ & $3.53 \mathrm{E}+00$ \\
\hline & $\mathrm{E}$ & $\$ 40,823$ & None & none & none & none \\
\hline \multirow[t]{5}{*}{ Primary Clarifier } & A & $\$ 61,841$ & None & $3.80 \mathrm{E}-07$ & $8.42 \mathrm{E}-02$ & none \\
\hline & $\mathrm{B}$ & $\$ 11,993$ & None & none & $2.17 \mathrm{E}-01$ & none \\
\hline & $\mathrm{C}$ & $\$ 63,075$ & $1.28 \mathrm{E}-04$ & $4.21 \mathrm{E}-07$ & $9.14 \mathrm{E}-04$ & $2.17 \mathrm{E}-01$ \\
\hline & $\mathrm{D}$ & $\$ 13,299$ & $3.70 \mathrm{E}-04$ & $1.16 \mathrm{E}-07$ & 2.64E-03 & $6.27 \mathrm{E}-01$ \\
\hline & $\mathrm{E}$ & $\$ 28,429$ & None & none & none & none \\
\hline \multirow[t]{5}{*}{ Secondary Clarifier } & A & $\$ 16,010$ & None & $1.28 \mathrm{E}-12$ & $1.64 \mathrm{E}-05$ & none \\
\hline & B & $\$ 11,993$ & None & none & $1.69 \mathrm{E}-05$ & none \\
\hline & $\mathrm{C}$ & $\$ 17,290$ & $4.01 \mathrm{E}-08$ & $1.39 \mathrm{E}-11$ & 5.31E-07 & $4.25 \mathrm{E}-05$ \\
\hline & $\mathrm{D}$ & $\$ 13,299$ & $4.21 \mathrm{E}-08$ & $1.32 \mathrm{E}-11$ & $5.58 \mathrm{E}-07$ & $4.39 \mathrm{E}-05$ \\
\hline & $\mathrm{E}$ & $\$ 29,854$ & None & none & none & none \\
\hline \multirow[t]{5}{*}{ Pump House } & A & $\$ 69,587$ & None & 4.57E-08 & $1.2 \mathrm{E}-01$ & none \\
\hline & B & $\$ 14,385$ & None & none & $2.5 \mathrm{E}-01$ & none \\
\hline & $\mathrm{C}$ & $\$ 71,471$ & $2.70 \mathrm{E}-04$ & $1.31 \mathrm{E}-07$ & $1.61 \mathrm{E}-03$ & $3.65 \mathrm{E}-01$ \\
\hline & D & $\$ 16,437$ & $5.67 \mathrm{E}-04$ & $1.79 \mathrm{E}-07$ & $3.39 \mathrm{E}-03$ & $7.68 \mathrm{E}-01$ \\
\hline & $\mathrm{E}$ & $\$ 40,121$ & None & none & none & none \\
\hline
\end{tabular}




\section{PUBLICATION AND DISTRIBUTION OF THE PROTOCOL}

In order for the protocol to become a useful tool at DOE sites, it needs to be widely distributed. In order to accomplish this, the protocol was publicized and distributed through the following:

Web page located at web.ead.anl.gov/authrel

Presentations at IDS 2000 and Spectrum 2000

Distribution of protocol to other DOE sites via the D\&D Focus Area, NETL

For further information, or a copy of the protocol, please contact S.Y. Chen, Argonne National Laboratory-East, Phone: (630) 252-7695, E-mail: sychen@anl.gov. 


\section{PROJECT PERFORMANCE RESULTS}

Project planning included defining milestones - tasks to be completed at specific points throughout the duration of the project. For the most part, milestones were met on time or before. The only exception was publication of the Concrete Protocol, which was delayed because of travel schedules and concurrent milestones for other projects and the wide distribution of the protocol which was had printing delays (although some distribution of the electronic copies were completed before 8/30/2000.

\begin{tabular}{lcc}
\hline \multicolumn{1}{c}{ Milestone } & Due Date & Completion Date \\
\hline $\begin{array}{l}\text { A1 Develop a draft protocol for the free release of concrete } \\
\text { A2 Develop a second draft protocol for the free release of } \\
\quad \text { concrete }\end{array}$ & $2 / 28 / 2000$ & $2 / 28 / 2000$ \\
A3 Determine the required protocol enabling & $4 / 15 / 2000$ & $4 / 15 / 2000$ \\
$\quad$ documentation & $4 / 30 / 2000$ & $3 / 22 / 2000$ \\
A4 Publish a final protocol for the free release of concrete & $6 / 30 / 2000$ & $7 / 07 / 2000$ \\
$\begin{array}{l}\text { A5 Complete required protocol enabling documentation at } \\
\quad \text { the INEEL }\end{array}$ & $8 / 30 / 2000$ & $7 / 20 / 2000$ \\
A6 Distribute the protocol for free release of concrete & & \\
$\quad$ within the DOE complex & $8 / 30 / 2000$ & $9 / 30 / 2000$ \\
$\begin{array}{l}\text { B1 Use the concrete free release protocol when planning } \\
\quad \text { D\&D of an INEEL facility }\end{array}$ & $9 / 30 / 2000$ & $8 / 30 / 2000$ \\
$\begin{array}{l}\text { C1 Develop the presentation for the D\&D Focus Area Mid- } \\
\quad \text { year review }\end{array}$ & $4 / 5 / 2000$ & $3 / 15 / 2000$ \\
\hline
\end{tabular}

The ASTD Reuse of Concrete within DOE from D\&D project involved a number of tasks, each of which led to several accomplishments. Planning and funding are important constituents of any project, so several accomplishments revolve around management and funds transfer from INEEL to the other sites. In February 2000, a Change Control was completed to revise the project scope and schedule. INEEL transferred \$50,000 to Argonne National Laboratory-East through an Interoffice Work Order. In May 2000, the INEEL completed paperwork to extend the contract with ANL-E to the end of the fiscal year and to transfer remaining ANL-E funds to them to complete their scope of work. Then, in June 2000, an FY01 planning package and TTP revision were completed to define the work scope for $\$ 35,000$, which was "prepaid" in FY00, to be used during FY01. With the new funds, a draft ASTM Standard for Reuse of Concrete will be written and presented to the ASTM D\&D subcommittee. In addition, the INEEL will take steps to deploy the protocol on a building during D\&D.

A major part of project management and planning is communication between team members at different sites. In addition to regular project conference calls every other Thursday at 10:00 AM EDT (9:00 CDT, 8:00 MDT), the project members exchanged other phone calls, corresponded through e-mail, and met once in person. S.Y. Chen and Sunita Kamboj of ANL-E and Frank Parker of Vanderbilt University visited the INEEL on March 7, 2000 for a team meeting to review the draft protocol and discuss how it relates to existing INEEL procedures. INEEL personnel from Radiation Engineering, D\&D Operations, and Environmental Remediation Technologies attended the meeting, which was very successful. A detailed review of the protocol helped the INEEL team understand its intent and function and provided them an opportunity to give feedback to ANL-E. Further discussions provided ANL-E with details about the INEEL radiation survey and release procedures, D\&D Operations and how disposal 
options are currently evaluated, and the concrete crusher. The team reviewed candidate INEEL facilities and selected the Sewage Treatment Plant at Central Facilities Area as a test case for the new protocol. Following the meeting, the INEEL completed action items discussed and sent information for the protocol to ANL-E, including INEEL procedures and data on the Central Facilities Area Sewage Treatment Plant concrete volumes, contaminants, facility and process descriptions, and disposition methods chosen. In addition, they sent a summary of common concrete cleaning methods with their initial and operational costs and throughput rates.

While project management, planning, and communication were vital to the project's success, the ultimate purpose of the project was to create the concrete free release protocol. The INEEL received the preliminary draft of the Protocol for the Reuse of Concrete from ANL-E on February 29, 2000 and reviewed the document. ANL-E completed the second draft of the general protocol on schedule, on April 15, and the INEEL team reviewed it and sent comments to ANL-E. ANL-E completed a final draft of the general protocol and sent it out for review on June 5. The INEEL returned comments to ANL-E. ANL-E incorporated comments on the final draft of the protocol and published it July 7. This slip from the June 30 goal was due to extremely busy travel schedules, simultaneous milestones on other projects with regulatory drivers, and a shortage of manpower, as one key player was out of the office.

Besides completing drafts of the protocol, ANL-E also finished a draft case study analysis of the INEEL CFA STP facility in June 2000. The case study evaluated the costs and risks of the various disposition alternatives. The INEEL reviewed the draft and returned comments to ANL-E, who then prepared a second draft, which was sent out for comments in early August. ANL-E published the final draft on electronically by $8 / 30 / 2000$. It will be available in printed form by $9 / 30 / 2000$ for those requesting it.

Various presentations and papers have helped publicize the project and the concrete protocol. A presentation was completed at the DDFA mid-year review, held March 28-30 in Morgantown, WV. Project personnel also submitted and presented a paper at the Spectrum 2000 conference. In addition, ANL-E presented a paper entitled "Protocols for Free Release of Concrete" to the IDS 2000 conference held June 12-16 in Knoxville, TN. The presentation was well received, with comments from Oak Ridge National Laboratory that they could have used the protocol to disposition concrete on a project completed over the last year. In addition, private industry people from the United Kingdom expressed an interest in using the protocol in the future. Rocky Flats Environmental Technology Site also requested information about the protocol. They are interested in applying it to reuse concrete at their site, even though they completed a similar project for non-contaminated concrete.

Rocky Flats implemented a procedure for releasing concrete for reuse as roadbed material. A comparison of the differences between the Rocky Flats Protocol for Concrete Recycle and the ASTD Concrete Reuse project showed that the projects are complimentary rather than redundant. The Rocky Flats Protocol focuses on releases that meet existing release criteria and the effects of implementationsuch as noise and inert dust levels - on the nearby community. The ASTD Reuse of Concrete within DOE from D\&D project produced a DOE-wide guideline for developing release standards and comparing the risks and costs of various disposal options.

The project was funded very late in FY99, with work beginning in FY00. The total project funding level was $\$ 403 \mathrm{~K}$. Of this amount, $\$ 150 \mathrm{~K}$ was allocated to Argonne National Laboratory East, and \$253K was allocated to the INEEL. During FY00, all of the planned project goals and milestones were met, with approximately $\$ 90 \mathrm{~K}$ of funding remaining. These funds, along with $\$ 35 \mathrm{~K}$ awarded in June 2000 , will be carried over into FY01 to complete additional scope. In FY01, a draft American Society for Testing and Materials (ASTM) standard for reuse of concrete will be developed and presented to the ASTM D\&D sub-committee for review. In addition, efforts will be made to facilitate use of the Protocol for 
Development of Authorized Release Limits for Concrete at U.S. Department of Energy Sites at a DOE site during D\&D of a facility containing contaminated concrete. 


\section{CONCLUSION}

Overall, the protocol is well done, proceeds along logical decision paths, and is expected to be a useful tool for the industry. The protocol will show DOE and regulators all the ramifications of releasing concrete with residual radioactivity, and with this information, releases may become possible. Having a consistent, well documented approach for estimating the doses and costs for various alternatives will aid D\&D project managers in their decisions and will allow DOE and regulators to make consistent, objective decisions about releasing these materials. 


\section{REFERENCES}

1. F. L. Parker et al, Reuse of Concrete from Contaminated Structures, DE-FG05-94OR22343, January 29, 1999.

2. S. Y. Chen et al, "Authorized Release of DOE's Non-Real Property: Process and Approach," The Radiation Protection Journal, Vol. 77, No. 2, August 1999, pp. S40-S48.

3. S. Y. Chen et al, "Protocols for Implementing DOE Authorized Release of Radioactive Scrap Metals," The Radiation Protection Journal, Vol. 77, No. 5, November 1999, pp. S2-S11.

4. DOE Order 5400.5, "Radiation Protection of the Public and the Environment," U.S. Department of Energy, February 8, 1990.

5. U.S. Department of Energy, Draft Handbook for Controlling Release for Reuse or Recycle of Property Containing Residual Radioactive Material, Interim Guide - for Interim Use and Comment, June 1997.

6. J. J. Arnish et al, Protocol for Development of Authorized Release Limits for Concrete at U.S. Department of Energy Sites, doc. \#, July 7, 2000.

7. S. Kamboj et al, INEEL Case Study Using Authorized Release Concrete Protocol for Central Facilities Area 691, Sewage Treatment Plant, doc. \#, August 31, 2000.

8. D. J. Kenoyer and S. A. LaBuy, Concrete Recycling Feasibility at the INEL, EDF-ER-15, June 16, 1994. 
Appendix A

Authors/Biographies 



\title{
Appendix A \\ Authors/Biographies
}

\author{
Ann Marie Phillips \\ Staff Engineer \\ Bechtel BWXT Idaho, LLC \\ P.O. Box 1625, MS 3765 \\ Idaho Falls, Idaho 83415-3765, U.S.A. \\ Phone: (208) 526-6877 \\ Fax: (208) 526-0425 \\ E-mail: aqs@inel.gov \\ Relevant Experience:
}

Worked as a mechanical engineer and project manager for fifteen years, including work on retrieval and containment of buried waste and decontamination and decommissioning of nuclear facilities.

\section{Educational Background:}

B.S. - Mechanical Engineering, University of Minnesota

\author{
Leslie J. Foster \\ Student \\ INEEL Academic Center for Excellence (ACE) \\ Bechtel BWXT Idaho, LLC \\ P.O. Box 1625, MS 3710 \\ Idaho Falls, Idaho 83415-3710, U.S.A. \\ Phone: (208) 526-4431 \\ Fax: (208) 526-6802 \\ E-mail: fostlj@inel.gov \\ Relevant Experience:
}

Worked on the Accelerated Site Technology Deployment Integrated Decontamination and Decommissioning (ASTD ID\&D) Project during the summer of 1999.

\section{Educational Background:}

AAS - General Studies, Ricks College

Currently a senior at Brigham Young University, pursuing a B.S. in Mathematics 
Julia L. Tripp

Advisory Engineer

Bechtel BWXT Idaho, LLC

P.O. Box 1625. MS 3720

Idaho Falls, Idaho 83415-3720, U.S.A.

Phone: (208) 526-3876

Fax: (208) 526-6802

E-mail: jtri@,inel.gov

\section{Scope of Present Duties:}

Development and evaluation of technologies to support Decontamination and Decommissioning and Environmental Restoration activities.

\section{Relevant Experience:}

Engineer at the INEEL for the past 17 years. Set up and managed the Radioactive Liquid Waste Reduction group at the INEEL that focuses on testing and implementing a variety of decontamination techniques to reduce waste generation.

\section{Educational Background:}

B.S. - Chemical Engineering, University of Idaho

\section{Richard H. Meservey}

Program Manager

Bechtel BWXT Idaho, LLC

P.O. Box 1625, MS 3710

Idaho Falls, Idaho 83415-3710, U.S.A.

Phone: (208) 526-1834

Fax: (208) 526-6802

E-mail: rhm@inel.gov

\section{Scope of Present Duties:}

Development and evaluation of technologies to support Decontamination and Decommissioning and Environmental Restoration activities.

\section{Relevant Experience:}

Set up and managed the INEEL D\&D program for 15 years. During that time 24 facilities were decommissioned and returned to unrestricted use. No significant accident or incident occurred as a result of these activities.

\section{Educational Background:}

B.S. - Physics, Western Illinois University

M.S. - Physics, University of Idaho 


\section{S.Y. Chen}

Argonne National Laboratory

9700 South Cass Avenue

Chicago, Illinois 60439, U.S.A.

Phone: (630) 252-7695

Fax: (630) 252-4611

E-mail: sychen@anl.gov

\section{Relevant Experience:}

S.Y. Chen is currently Manager in Risk and Waste Management for the Environmental Assessment Division of Argonne National Laboratory, Argonne, Illinois. He is a member of the Health Physics Society and of the American Nuclear Society. He is also a Certified Health Physicist of the American Board of Health Physics. He is currently a member of the National Council on Radiation Protection and Measurements (NCRP). He also chairs NCRP's Scientific Committee 87-4 on the management of radioactive scrap metal management. For the past years he chaired the Contamination Limit Section of the Health Physics Society Standards Committee in developing release standards for materials containing residual radioactivity for the American National Standards Institute (i.e., ANSI N13.12 Standards). In his current capacity at Argonne, Dr. Chen has developed an Integrated Risk Assessment Program to support U.S. Department of Energy (DOE) site cleanup activities. His group has been noted for the development of several environmental pathway models for DOE, including RESRAD for cleanup assessments, RISKIND for transportation consequence analyses, TSD-DOSE for assessment of radiological doses from treatment and disposition of mixed wastes, and P2Pro (RSM) management tool for authorized release of radioactive scrap metals.

\section{Educational Background:}

B.S. - Nuclear Engineering, National Tsing Hua University in Taiwan.

M.S. - Nuclear Engineering, University of Illinois at Champaign-Urbana, Illinois.

Ph.D. - Nuclear Engineering, University of Illinois 


\section{Sunita Kamboj}

Environmental Systems Engineer

Argonne National Laboratory

9700 South Cass Avenue

Chicago, Illinois 60439, U.S.A.

Phone: (630) 252-5457

Fax: (630) 252-4624

E-mail: skamboj@anl.gov

\section{Relevant Experience:}

Supporting U.S. Department of Energy (DOE) site cleanup activities. Working on the development of environmental characterization decision tools to be used for expanding pathway analysis capabilities in cleanup activities. Worked on many projects related to release of real and non-real property for reuse and recycle. Developed release criteria for contaminated soil and structures for many sites.

\section{Educational Background:}

M.S. 1990 Georgia Institute of Technology

Ph.D. 1994 Georgia Institute of Technology

CHP. 1997 American Board of Health Physics

\section{John J. Arnish}

Argonne National Laboratory

9700 South Cass Avenue

Chicago, Illinois 60439, U.S.A.

Phone: (630) 252-4983

Fax: (630) 252-4624

E-mail: jarnish@anl.gov

\section{Relevant Experience:}

John Arnish is an assistant scientific systems developer for the Environmental Assessment Division at Argonne National Laboratory, Argonne, IL. He is a member of the Health Physics Society. Mr. Arnish is a co-developer of radiological assessment computer codes: RESRAD, RESRAD-BUILD, RESRADRECYCLE, TSD-DOSE and P2Pro(RSM). He is also involved with the development of authorized release limits for residual radioactive material at DOE sites.

\section{Educational Experience:}

B.S. - Physics, Southern Illinois University

M.S. - Nuclear Engineering, University of Tennessee, Knoxville TN. 
Frank L. Parker

Professor of Environmental Engineering

Vanderbilt University

Box 1596 Station B

Nashville, Tennessee, 37235 U.S.A.

Phone: (615) 343-2371

Fax: (615) 322-3365

ParkerFL@vuse.vanderbilt.edu

\section{Scope of Present Duties/Relevant Experience:}

Frank L. Parker graduated from MIT and Harvard and is Distinguished Professor of Environmental Engineering at Vanderbilt University. He is a member of the National Academy of Engineering. He has served as the Head of Radioactive Waste Disposal Research at both the Oak Ridge National Laboratory and the International Atomic Energy Agency. He has served as Chairman of the Board of Radioactive Waste Management of the National Academy of Sciences/National Research Council. He has directed the radioactive waste research activities at both the Beijer Institute of the Swedish Academy of Sciences and the International Institute for Applied Systems Analysis in Austria (IIASA). At IIASA, he and his team are investigating radioactive waste problems at the 3 spent nuclear fuel reprocessing sites in Russia. For the USDOE, he has just completed a major study on the recycling of concrete from radioactively contaminated buildings. If the recommendation is implemented, it has the potential of saving over one billion dollars in cleanup costs.

\section{Educational Background:}

B.S. 1948 Massachusetts Institute of Technology

M.S. 1950 Harvard University

Ph.D. 1955 Harvard University 